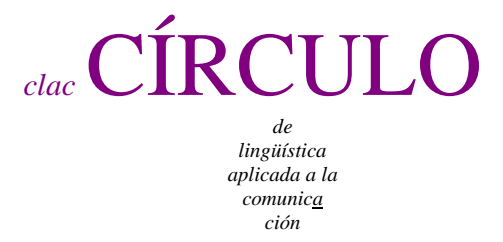

$69 / 2017$

\title{
DISCOURSE: THE JOURNAL OF THE SPEECH COMMUNICATION ASSOCIATION OF SOUTH DAKOTA
}

https://sites.google.com/site/sdspeechcomm/scasd-journal

Discourse: The Journal of the Speech Communication Association of South Dakota publishes original articles from academics and professionals of all levels in communication, rhetoric, forensics, theatre and other speech-related or theatre-related activities. As such, the journal embraces the interdisciplinary nature of the field of speech communication. The journal accepts articles with the diverse range of concerns of the theoretical to the applied, from the humanities to the social sciences, and from the scholarly to the pedagogical. The journal's primary audience is constituted of teachers and scholars in communication, theatre, and English; and coaches of speech, debate and theatre performance activities.

Volume 3, Fall 2016

Anthony M. Wachs: Message from the Editor

Invited Article : Ryan K. Clark: Should a Dropped Argument Always be Treated as a Conceded Argument?

Discourse: the journal of the speech communication association of South Dakota.

Círculo de Lingüística Aplicada a la Comunicación 69, 347-348.

http://www.ucm.es/info/circulo/no69/discourse.pdf

http://revistas.ucm.es/index.php/CLAC

http://dx.doi.org/10.5209/CLAC.55325

(C) 2017 Círculo de Lingüística Aplicada a la Comunicación (clac)

Universidad Complutense de Madrid. ISSN 1576-4737. http://www.ucm.es/info/circulo 
Research Articles and Theoretical Perspectives

Andie Malterud and Jenn Anderson: Weight-Based Stigma and Self-Esteem: A Test and Extension of the Stigma Communication Model

Matthew H. Barton and Kevin A. Stein : Listening to Unheard Voices: Nurses' Communication Experiences with the NRS Pain Scale

Kristopher Copeland: An Examination of the Narratives of Lottery-Scholarship Legislation

Rick Malleus : Enemies of the State: The Symbolic Annihilation of White-Zimbabwean Identity in the Twenty-First Century

G.I.F.T.S. (Great Ideas For Teaching Students)

Colleen Arendt Blending: Theory and Application: Student-Authored Organizational Case Studies

Claire H. Procopio : Closing the Assessment Loop in the Basic Communication Course

David H. Kahl, Jr : Men's Rights Activists and the Ray Rice Domestic-Violence Case: Using Critical Communication Pedagogy to Counter Hegemonic Masculinity

Brent Kice :Developing a Supportive Communication Climate for Virtual Task Groups

Jeffrey Brand: The American Pickers Demonstrates Communication Skills

Call for manuscripts volume 4, fall 2017 Deadline April 1st, 2017

Discourse: The Journal of the SCASD is seeking original manuscripts for Volume 4, to be published Fall 2017. Discourse is generalist in scope. As such, we seek theoretical, applied, and pedagogical (Great Ideas for Teaching-GIFT) manuscripts from the various interest areas of communication studies, including rhetoric, persuasion, mass media, organizational, interpersonal, and theater. Submissions are welcome from either in-state or out-of-state scholars at sdspeechcomm at gmail com. Authors are not required to be members of the Speech Communication Association of South Dakota. Manuscripts are accepted from academics and professionals of all levels in communication studies, education, forensics, theater and other speech-related or theaterrelated activities. Faculty, secondary educators, and students (i.e., graduate and advanced undergraduates) are encouraged to submit manuscripts. Please indicate whether the manuscript is being submitted to either (1) the theory and research or (2) the GIFT section of the journal. Research or GIFTs grounded in communication or theater theory are encouraged. All submissions undergo a review process with select manuscripts shortlisted for blind review by at least two peer scholars. Shortlisted authors must commit to a timeline for revision, resubmission and potential publication.

Published February 28, 2017.

Updated March 13, 2017 